\title{
Alkyne hydroarylation with Au N-heterocyclic carbene catalysts
}

\author{
Cristina Tubaro, Marco Baron, Andrea Biffis ${ }^{*}$ and Marino Basato
}

\section{Full Research Paper}

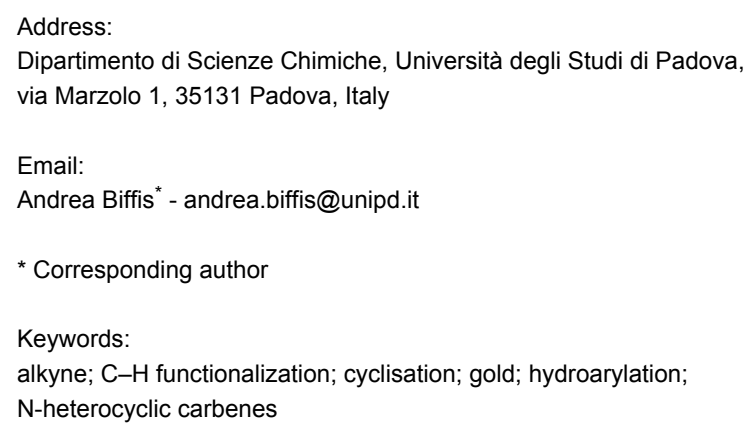

\begin{abstract}
Mono- and dinuclear gold complexes with N-heterocyclic carbene (NHC) ligands have been employed as catalysts in the intermolecular hydroarylation of alkynes with simple unfunctionalised arenes. Both mono- and dinuclear gold(III) complexes were able to catalyze the reaction; however, the best results were obtained with the mononuclear gold(I) complex IPrAuCl. This complex, activated with one equivalent of silver tetrafluoroborate, exhibited under acidic conditions at room temperature much higher catalytic activity and selectivity compared to more commonly employed palladium(II) catalysts. Moreover, the complex was active, albeit to a minor extent, even under neutral conditions, and exhibited lower activity but higher selectivity compared to the previously published complex $\mathrm{AuCl}\left(\mathrm{PPh}_{3}\right)$. Preliminary results on intramolecular hydroarylations using this catalytic system indicate, however, that alkyne hydration by traces of water may become a serious competing reaction.
\end{abstract}

\section{Introduction}

The hydroarylation of alkynes (Scheme 1) is arguably one of the most intensively studied reactions leading to aromatic $\mathrm{C}-\mathrm{H}$ bond functionalization [1-7]. In this reaction, the $\mathrm{C}-\mathrm{H}$ bond of

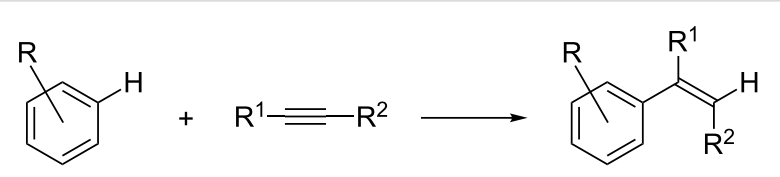

Scheme 1: Hydroarylation of alkynes. an arene adds formally trans to the triple bond of an alkyne, generally forming the thermodynamically less favoured cisarylalkene as the major product.

The study of this reaction was pioneered by the group of Fujiwara (hence the alternative name "Fujiwara reaction" for the intermolecular hydroarylation of alkynes) using mainly palladium(II) salts as catalyst [8-10]. Palladium complexes with $\mathrm{N}$-heterocyclic carbene (NHC) ligands have since been showcased as highly efficient catalysts for this reaction [11-14]. 
Alternative catalytic systems based on salts or complexes of other noble metals, such as platinum [15-17], gold [18,19], or rhodium [20], as well as of non-noble, electrophilic metals [2126] have also been successfully employed. Finally, an even greater number of catalysts have been proposed over the years to promote alkyne hydroarylation in an intramolecular fashion [1-7]. In such reactions, often simply termed cyclisation reactions, the arene and the alkyne are linked through a tether, the nature of which can range from simple alkyl groups to ether, amino, ester or amido groups; depending on the nature and length of the tether, different kinds of unsaturated poly(hetero)cyclic compounds can be conveniently synthesized.

Recently, the unique ability of gold centres to activate $\mathrm{C}-\mathrm{C}$ triple bonds towards nucleophilic attack has clearly emerged in the literature [27-34]. In the light of the above, it is surprising that the number of studies on the use of gold species as catalysts for alkyne hydroarylation is still quite limited. A substantial number of reports on the intramolecular cyclisation of arenes with tethered alkyne moieties using gold(I) or, to a lesser extent, gold(III) catalysts can be found in the literature [35-46]; however, only one additional example, beyond the two early reports by Reetz and Sommer [18] and by Shi and He [19], of gold-catalysed intermolecular hydroarylation has been described, albeit concerning 2-substituted oxazoles as the reaction partner [47]. Investigations on the intramolecular variant have focused mainly on the nature of the aromatic moiety that adds to the alkyne, and on the nature and/or length of the tether, whereas concerning the alkyne moiety, only terminal, electronrich alkyne groups (propargylic moieties in most instances) were employed, with very few exceptions $[36,40,44]$. Finally, concerning the nature of the employed catalysts, simple gold salts or phosphino complexes of gold(I) were utilized in the majority of cases, although in recent years an increasing number of studies have been dealing with the application of NHC complexes of gold for these and related reactions [48-53].

We have an ongoing interest in the development of novel catalysts for the hydroarylation of alkynes and have extensively investigated the ability of palladium(II) complexes with chelating N-heterocyclic dicarbene ligands to promote this reaction [12-14]. Recently, we have extended our interest in the organometallic chemistry of such ligands to group 11 metals, in particular gold(I) and gold(III) centers [54-56]. In the present contribution we would like to assess the catalytic efficiency of such gold complexes with NHC ligands for the hydroarylation of alkynes.

\section{Results and Discussion}

We recently reported on the synthesis of dinuclear gold(I) complexes with bridging dicarbene ligands [55], as well as on the preparation of the corresponding dinuclear gold(III) analogues, which are obtained from the former upon oxidation with bromine [54]. Complexes I-V were now tested as catalysts in standard intermolecular hydroarylation reactions, together with two mononuclear gold complexes previously reported in the literature, namely complexes VI (also termed IPrAuCl) [57] and VII (also termed $\mathrm{IPrAuBr}_{3}$ ) [58] (Figure 1).

The standard reaction between pentamethylbenzene and ethyl propiolate (Scheme 2) was initially taken as the benchmark for catalyst evaluation. Initial attempts were performed at room

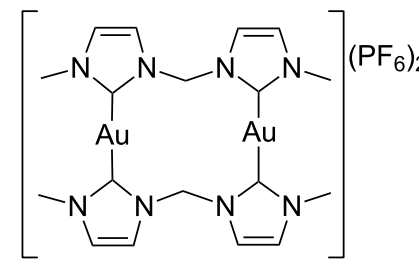

I

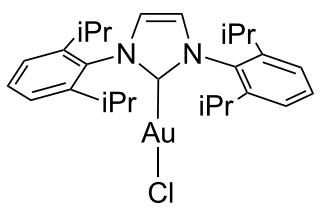

VI<smiles>[R]N1C=CN([Y])C1N(Br)C1N([Y])C=CN1[Y](Br)(Br)C(Br)(Br)C1N([R])C=CN1CC</smiles>

II: $\mathrm{R}=\mathrm{Me}, \mathrm{Y}=\mathrm{CH}_{2}$

III: $\mathrm{R}=\mathrm{Me}, \mathrm{Y}=\mathrm{CH}_{2} \mathrm{CH}_{2}$

IV: $\mathrm{R}=\mathrm{Me}, \mathrm{Y}=m$-xylylene

V: $R=\mathrm{Cy}, \mathrm{Y}=\mathrm{CH}_{2}$

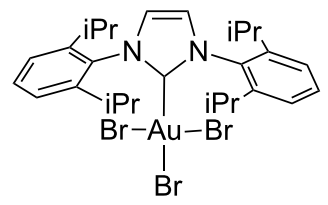

VII 
<smiles>Cc1cccc(C)c1C</smiles>

$1\{1\}$<smiles>[C+]C#CCOCC</smiles>

$2\{1\}$<smiles>CCOC=Cc1c(C)c(C)c(C)c(C)c1C</smiles>

$3\{1,1\}$

Scheme 2: Hydroarylation of ethyl propiolate with pentamethylbenzene.

temperature $\left(25^{\circ} \mathrm{C}\right)$ with very low levels of complex II as catalyst $(0.005 \mathrm{~mol} \%)$ by using trifluoroacetic acid (HTFA) or $\mathrm{HBF}_{4}$ as acidic medium plus $0.02 \mathrm{~mol} \% \mathrm{AgTFA}$ or $\mathrm{AgBF}_{4}$, respectively, as co-catalyst to remove bromides from the coordination sphere of the gold centres, thereby liberating coordination sites at the metal and boosting its electrophilicity.

The obtained results established that the complex was inactive when HTFA was employed as the acidic medium, whereas $20 \%$ yield of the desired product $\mathbf{3}\{1,1\}$ was obtained after $18 \mathrm{~h}$ with $\mathrm{HBF}_{4}$. Consequently, a screening of the catalytic efficiency of the various complexes was carried out with the latter acidic medium; the amount of catalyst was increased tenfold (to $0.1 \mathrm{~mol} \% \mathrm{Au}$ ) in order to achieve faster reaction rates, whereas the amount of employed $\mathrm{AgBF}_{4}$ co-catalyst was always stoichiometrically equivalent to the amount of bromide in the employed complex. It should be mentioned that under these reaction conditions neither $\mathrm{AgBF}_{4}$ nor $\mathrm{HBF}_{4}$ promote the reaction, as previously demonstrated by us in investigations on related palladium(II) catalysts for the same reaction [13]. The conversion curves obtained with the various catalysts are reported in Figure 2.

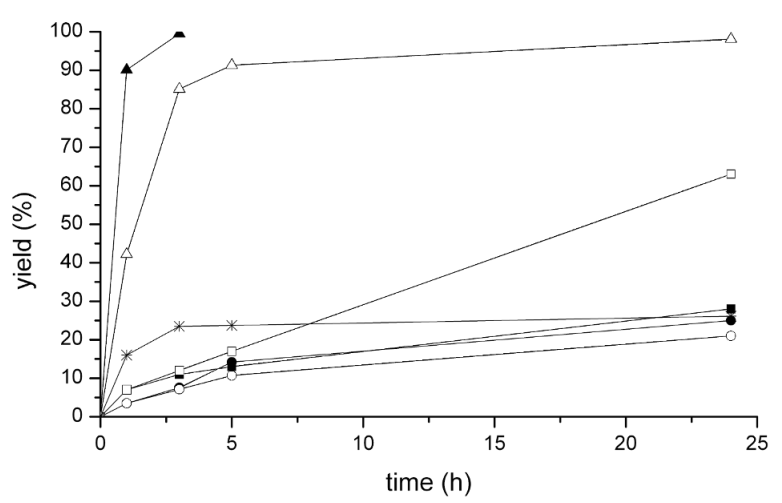

Figure 2: Yield in $\mathbf{3}\{1,1\}$ versus time diagram for the reaction of pentamethylbenzene and ethyl propiolate catalysed by complexes II-VII and $\mathrm{KAuBr}_{4}$ at room temperature in $\mathrm{HBF}_{4}$ and with added $\mathrm{AgBF}_{4}$ : complex II (black squares); complex III (circles); complex IV (squares); complex V (black circles); complex VI (black triangles); complex VII (triangles); $\mathrm{KAuBr}_{4}$ (asterisks). Reaction conditions: 1 equiv arene, 1 equiv alkyne, 1 equiv tetrafluoroboric acid, $0.1 \mathrm{~mol} \% \mathrm{Au}, 0.1-0.4 \mathrm{~mol} \% \mathrm{AgBF}_{4}, 1,2$-dichloroethane, $25^{\circ} \mathrm{C}$
As expected, the dinuclear dicarbene gold(I) complex I was found to be inactive for the reaction, as the NHC ligands saturate the coordination sphere of the gold(I) centres. On the other hand, the dinuclear dicarbene gold(III) complexes II-V, for which 4 equiv of $\mathrm{AgBF}_{4}$ with respect to the complex were added, turned out to be active. All dinuclear complexes exhibited very similar initial activity in the first few hours of reaction. This observation indicates that the reactivity of the complexes is not hampered by steric effects, as complexes with ligands of widely different steric bulk, such as II and V, exhibit similar performance. On the other hand, the complexes deactivate with time at different rates, depending on the nature of the employed dicarbene ligand. Complex IV turned out to be the catalyst most resistant to deactivation.

When catalysts VI, VII and $\mathrm{KAuBr}_{4}$ were employed together with the corresponding amount of $\mathrm{AgBF}_{4}$ co-catalyst, higher initial activities compared to the dinuclear dicarbene gold(III) catalysts were recorded. However, whereas $\mathrm{KAuBr}_{4}$ was very quickly and completely deactivated, catalysts VI and VII retained their activity, highlighting the importance of the NHC ligand in stabilizing the catalytically active species. Catalyst VI (IPrAuCl) was particularly efficient and able to effect over $90 \%$ yield in just $1 \mathrm{~h}$ with complete selectivity for the hydroarylation product. Remarkably, compared to the palladium(II) complexes with chelating N-heterocyclic dicarbene ligands previously investigated by us as catalysts for the same reaction under identical reaction conditions [13], complex VI exhibits higher catalytic activity and complete selectivity for the insertion of only one alkyne molecule into the aromatic $\mathrm{C}-\mathrm{H}$ bond, whereas the palladium(II) complexes predominantly yielded the product deriving from the insertion of two alkyne molecules. The catalytic efficiency of complexes VI and VII was evaluated with other arene and alkyne substrates under the same reaction conditions and the results are reported in Table 1.

The catalytic activity of the complexes remained high also with less substituted substrates, complex VI being systematically superior to complex VII. The selectivity of the reaction was, however, hampered by the formation of significant amounts of products deriving from the addition of two molecules of alkyne to the arene (product type 4), which was invariably recorded 
when more than one $\mathrm{C}-\mathrm{H}$ group was available for reaction. from insertion of more than one alkyne molecule into the same Other by-products that were observed on using Pd catalysis, arene $\mathrm{C}-\mathrm{H}$ bond, were however never detected with Au catasuch as, e.g., products of double-bond isomerisation or deriving lysts. Only in the case of $p$-xylene was the reaction again fully

Table 1: Hydroarylation of alkynes using gold NHC catalysts: screening of different arenes and alkynes. ${ }^{a}$<smiles>[R]c1ccccc1</smiles>

1<smiles>[R]#[R]</smiles>

2

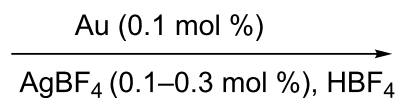

1,2-dichloroethane, $25^{\circ} \mathrm{C}$<smiles>[R]/C=C(\[R])c1cccc([R])c1</smiles>

3<smiles>[R]/C=C(\[R])c1cccc(/C([R])=C/[R])c1[R]</smiles>

4

2\{1\} $\mathrm{R}^{1}=\mathrm{H} ; \mathrm{R}^{2}=\mathrm{CO}_{2} \mathrm{Et}$

2\{2\} $R^{1}=\mathrm{Ph} ; \mathrm{R}^{2}=\mathrm{CO}_{2} \mathrm{Et}$

2\{3\} $\mathrm{R}^{1}=\mathrm{H} ; \mathrm{R}^{2}=n-\mathrm{Bu}$

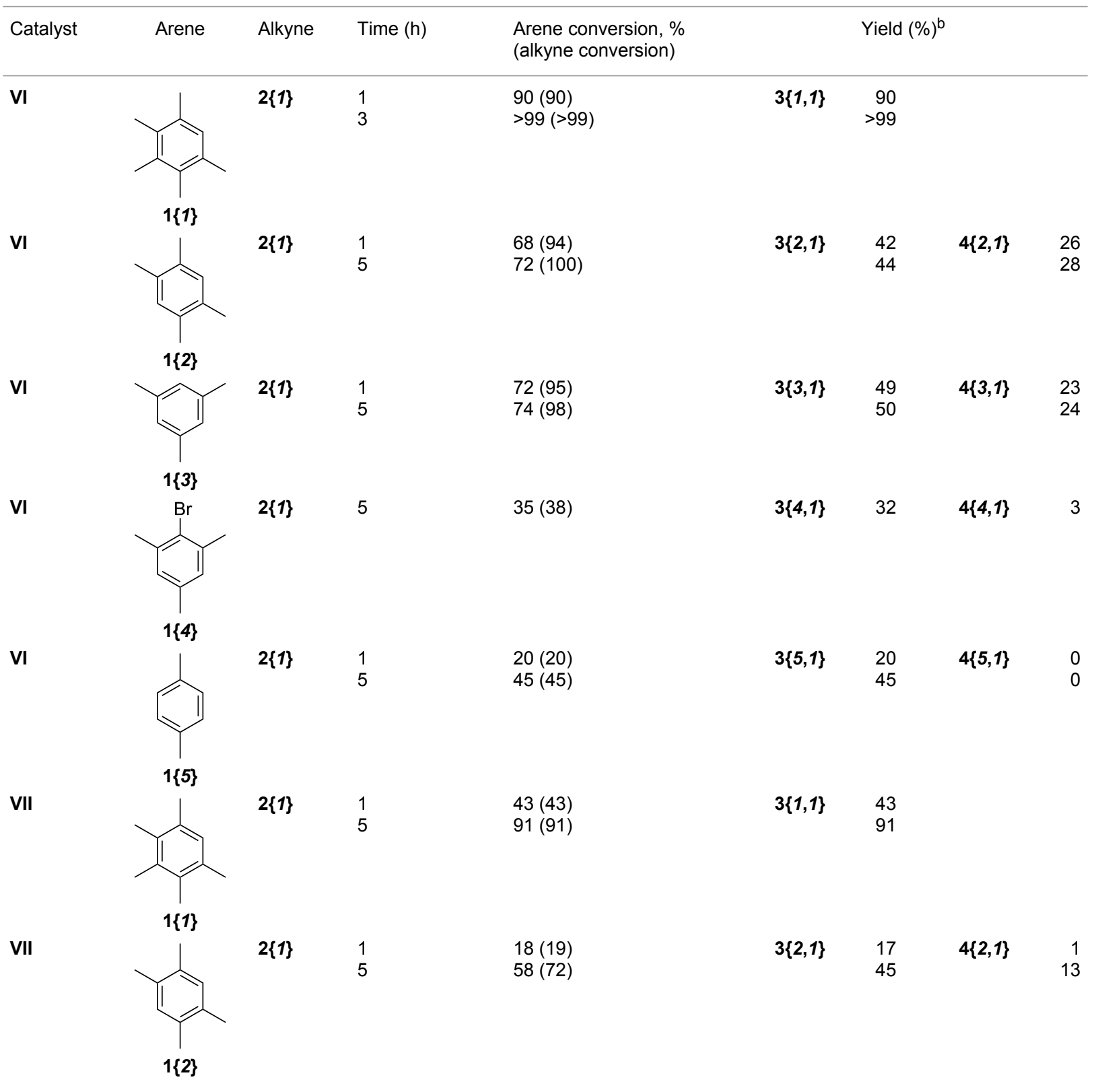




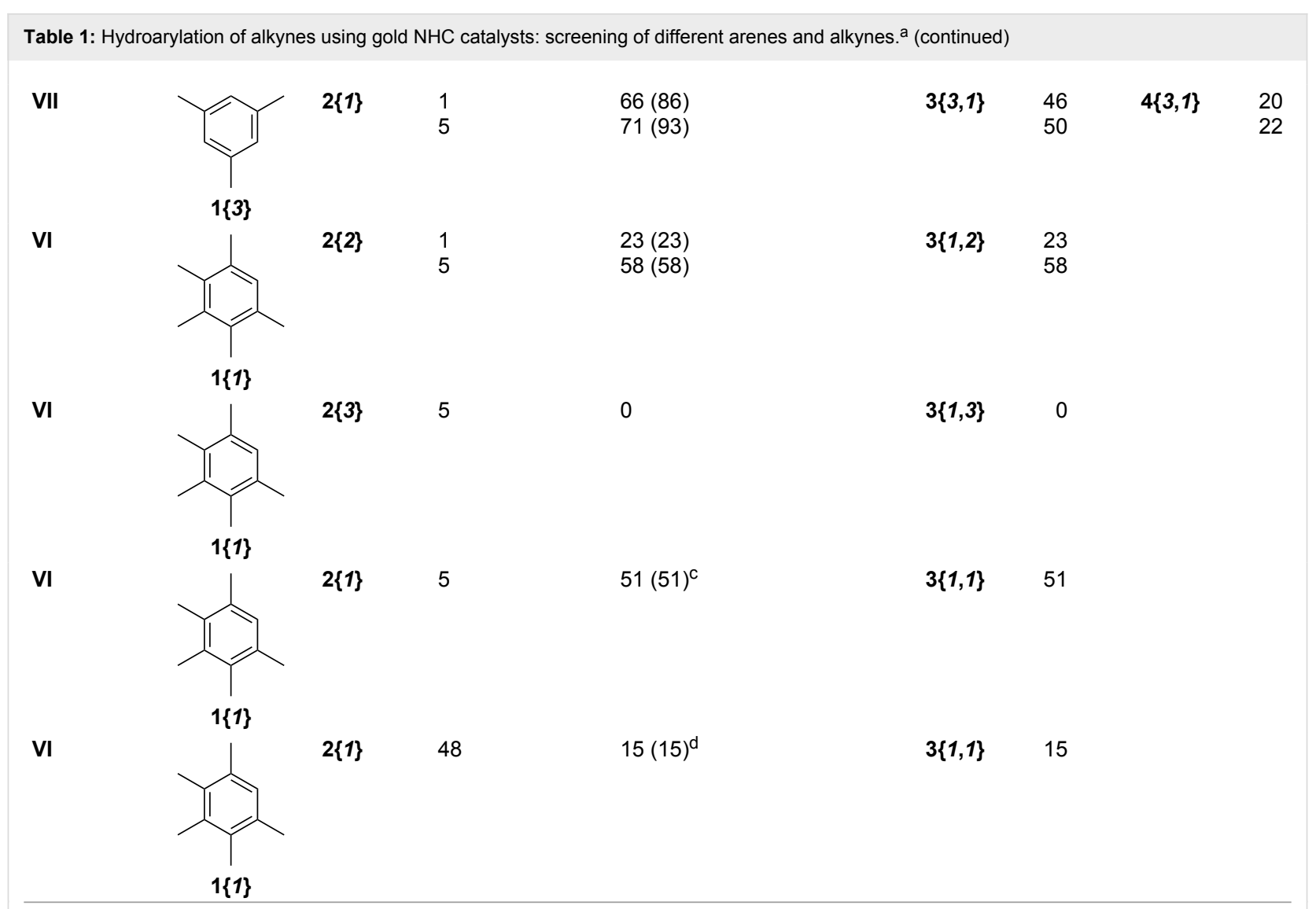

aReaction conditions: 1 equiv arene, 1 equiv alkyne, 1 equiv tetrafluoroboric acid, $0.1 \mathrm{~mol} \% \mathrm{Au}, 0.1$ or $0.3 \mathrm{~mol}_{\%} \mathrm{AgBF}_{4}, 1,2$-dichloroethane, $25^{\circ} \mathrm{C}$. bThe yield was determined by ${ }^{1} \mathrm{H}$ NMR spectroscopy. ${ }^{C}$ Reaction performed with trifluoroacetic acid. ${ }^{\mathrm{d}}$ Reaction performed without acid.

selective, albeit sluggish. Variations of the alkyne substrate made it apparent that electron-rich alkynes, such as 1-hexyne, are not viable substrates for this reaction, and that electronpoor, internal alkynes react only scarcely under these conditions.

The high catalytic activity of complex VI prompted us to evaluate its efficiency also under less acidic conditions. Hydroarylation of ethyl propiolate with pentamethylbenzene run with $0.1 \%$ VI and $0.1 \%$ AgTFA in HTFA yielded $51 \%$ pure monohydroarylated product after $5 \mathrm{~h}$. On the other hand, the reaction run with $0.1 \% \mathrm{VI}$ and $0.1 \% \mathrm{AgBF}_{4}$ under neutral conditions yielded only $15 \%$ product after $48 \mathrm{~h}$. Thus, the nature and amount of acid have a very strong influence on catalytic efficiency, as in the case of catalysis by palladium(II) NHC complexes [13]; in contrast to $\mathrm{Pd}$, though the catalyst remains slightly active even under neutral conditions. This result was expected, as in early examples of the use of gold catalysts for intermolecular alkyne hydroarylations the reaction was invariably done without acid addition, although much more forceful conditions (larger amount of catalyst, higher temperature, longer reaction times) were applied $[18,19,47]$. In order to have a closer comparison between the catalytic efficiency of VI and that of the previously employed gold(I) catalysts, such as $\mathrm{AuCl}\left(\mathrm{PPh}_{3}\right)$, we subjected complex VI to the same catalytic test performed by Reetz and Sommer with the phosphino complex (Scheme 3) [18]. The catalytic test performed with catalyst VI resulted in the exclusive formation of the hydroarylation product in $45 \%$ yield. Catalyst $\mathrm{AuCl}\left(\mathrm{PPh}_{3}\right)$ was reported instead to produce, under the same reaction conditions, the hydroarylation product in $56 \%$ yield, together with $28 \%$ yield of the product deriving from insertion of two alkyne molecules into two $\mathrm{C}-\mathrm{H}$ bonds of mesitylene [18]. Thus, it can be stated that catalyst VI is apparently less active but more selective under these neutral reaction conditions.

Finally, we preliminarily investigated the capability of complexes VI and VII to act as catalysts for intramolecular alkyne hydroarylation reactions. As mentioned in the Introduction, gold salts and complexes have been extensively employed for intramolecular cyclisations of this kind [35-46], but in most instances only terminal pendant alkynes have been employed as reacting groups. Furthermore, to the best of our knowledge substrates with amido tethers between the aryl and the alkyne, 


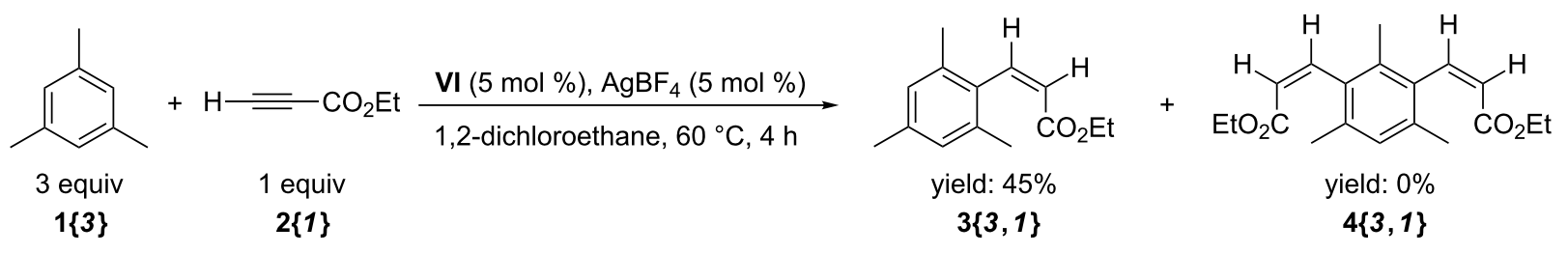

Scheme 3: Hydroarylation experiment with catalyst VI under neutral conditions.

such as substrates 5 (Scheme 4), have never been reported to undergo cyclisation with gold catalysts, whereas there are examples of the use of palladium catalysts with these substrates leading to different products in dependence on the reaction conditions: reaction under neutral conditions produces the 5-exo-dig cyclisation product 6 [59], whereas in the presence of an acid the 6-endo-dig product 7 is formed [60]. Thus, we set out to evaluate the reactivity of substrates $\mathbf{5}$ with catalysts VI and VII.

Under neutral conditions the reaction gave no yield in the desired cyclised product and the substrate was recovered unchanged in all cases. Therefore, we moved to investigate the reaction in the presence of trifluoroacetic acid, using a reaction protocol previously employed by Fujiwara for running analogous reactions with palladium(II) catalysts [60]. The results are reported in Table 2.

Catalyst VII was completely inactive even under acidic conditions with substrate $\mathbf{5}\{2\}$, whereas with substrate $\mathbf{5}\{\boldsymbol{1}\}$ it reacted sluggishly forming complex product mixtures containing also the 6-endo-dig cyclisation product $7\{2\}$. On the other hand, with complex VI moderate to very good conversions of the substrates were obtained, but the main reaction product was invariably the product of hydration of the triple bond $\mathbf{8}$, whereas the 6-endo-dig cyclisation product 7 was present in minor amounts. Gold(I) NHC complexes such as VI are known to be extremely efficient catalysts for alkyne hydration [61], hence it
Table 2: Intramolecular alkyne hydroarylation under acidic conditions. ${ }^{\text {a }}$

Substrate Catalyst Conversion $(\%)^{\mathrm{b}} \quad$ Yield $(\%)^{\mathrm{b}}$

\begin{tabular}{rrrrrrr}
\hline $\mathbf{5}\{1\}$ & VI & 89 & $\mathbf{7}\{1\}$ & 12 & $\mathbf{8}\{\mathbf{1}\}$ & 78 \\
$\mathbf{5}\{1\}$ & VII & 31 & $\mathbf{7}\{1\}$ & 10 & $\mathbf{8}\{\mathbf{1}\}$ & - \\
$\mathbf{5}\{2\}$ & VI & 54 & $\mathbf{7}\{2\}$ & 7 & $\mathbf{8}\{\mathbf{2}\}$ & 47 \\
$\mathbf{5}\{2\}$ & VII & 0 & $\mathbf{7}\{2\}$ & 0 & $\mathbf{8}\{\mathbf{2}\}$ & 0 \\
\hline
\end{tabular}

aReaction conditions: 1 equiv substrate, 20 equiv trifluoroacetic acid, $1 \mathrm{~mol} \% \mathrm{Au}, 1 \mathrm{~mol} \% \mathrm{AgBF}_{4}$, 1,2-dichloroethane, room temperature, $24 \mathrm{~h}$. ${ }^{\mathrm{b}}$ The conversion and the yields were determined by ${ }^{1} \mathrm{H}$ NMR spectroscopy.

can be expected that alkyne hydration by traces of water may become a serious competitive reaction despite the low concentration of water in the reaction mixture. On the basis of the above, it can be hypothesised that in order to steer the reaction towards the hydroarylation product, more activating, hence electron-donating substituents should be installed on the aryl ring. Experiments towards this goal are currently underway.

\section{Conclusion}

In conclusion, we have demonstrated that gold complexes with $\mathrm{N}$-heterocyclic carbenes are active catalysts for alkyne hydroarylations under acidic conditions. Mononuclear complexes appear more active than dinuclear ones, and gold(I) complexes are more active and selective than analogous gold(III) complexes. Under neutral reaction conditions, mononuclear gold(I) NHC complexes appear less active but more selective than the<smiles>[R]N(C(=O)C#Cc1ccccc1)c1ccccc1</smiles><smiles>[R]N1C(=O)/C(=C\c2ccccc2)c2ccccc21</smiles><smiles>[R]n1c(=O)cc(-c2ccccc2)c2ccccc21</smiles><smiles>[R]N(C(=O)CC(=O)c1ccccc1)c1ccccc1</smiles>

5\{1\} $\mathrm{R}=\mathrm{Me}$

$5\{2\} R=H$

6\{1 $\} \mathrm{R}=\mathrm{Me}$

$6\{2\} R=H$
$7\{1\} \mathrm{R}=\mathrm{Me}$

$7\{2\} R=H$
$8\{1\} \mathrm{R}=\mathrm{Me}$

$8\{2\} R=H$ 
corresponding triphenylphosphine complexes. Finally, tests performed on the intramolecular hydroarylation of substrates $\mathbf{5}\{\mathbf{1}\}$ and $\mathbf{5}\{2\}$ indicate that the reaction does not take place under neutral conditions, whereas under acidic conditions products of alkyne hydration by traces of water present in the reaction mixture are mainly formed, together with low yields of the 6-endo-dig cyclisation product. Possibly the installation of an electron-donating group on the aryl ring will improve the efficiency of the hydroarylation process.

\section{Experimental}

All manipulations were carried out using standard Schlenk techniques under an atmosphere of dry argon or dinitrogen. The reagents were purchased at Sigma-Aldrich or Merck as highpurity products and generally used as received. All solvents were dried by standard procedures and distilled under dinitrogen prior to use. Complexes I [55], II-V [54] and VII [58], as well as substrates $\mathbf{5}\{\mathbf{1}\}$ and $\mathbf{5}\{\mathbf{2}\}$ [59] were prepared according to literature procedures. NMR spectra were recorded on a Bruker Avance $300 \mathrm{MHz}\left(300.1 \mathrm{MHz}\right.$ for ${ }^{1} \mathrm{H}$ and $75.5 \mathrm{MHz}$ for ${ }^{13} \mathrm{C}$ ); chemical shifts $(\delta)$ are reported in units of parts per million (ppm) relative to the residual solvent signals.

Catalytic tests. General procedure for the intermolecular hydroarylation: In a $100 \mathrm{~mL}$ three-necked, round-bottomed flask were placed the arene $(13.2 \mathrm{mmol})$, the Au complex ( $0.013 \mathrm{mmol}$ for mononuclear complexes, $0.0065 \mathrm{mmol}$ for dinuclear complexes) and $\mathrm{AgBF}_{4}(0.013 \mathrm{mmol}$ to $0.052 \mathrm{mmol}$, depending on the Au complex employed). The flask was evacuated and filled with argon, after which the acid (13.2 mmol) and 1,2-dichloroethane (the quantity necessary to reach a total volume of $6.3 \mathrm{~mL}$ ) were added. Finally, the alkyne $(13.2 \mathrm{mmol})$ was introduced, and the flask was placed in a water bath thermostated at $25{ }^{\circ} \mathrm{C}$ and vigorously stirred. Aliquots of the reaction mixture (around $0.2 \mathrm{~mL}$ ) were periodically withdrawn from the reactor and analysed by ${ }^{1} \mathrm{H}$ NMR.

General procedure for the intramolecular hydroarylation: In a Schlenck tube were placed the substrate $(1.00 \mathrm{mmol})$, the $\mathrm{Au}$ complex $(0.010 \mathrm{mmol})$ and $\mathrm{AgBF}_{4}(0.010 \mathrm{mmol})$. The flask was evacuated and filled with argon, after which 1,2dichloroethane $(2 \mathrm{~mL})$ and trifluoroacetic acid $(1.5 \mathrm{~mL}$, $20 \mathrm{mmol}$ ) were added. The resulting mixture was vigorously stirred at room temperature for $24 \mathrm{~h}$. The reaction mixture was subsequently poured into a saturated aqueous $\mathrm{NaCl}$ solution $(20 \mathrm{~mL})$ and neutralized with a saturated aqueous $\mathrm{NaHCO}_{3}$ solution. The residual substrate and products were extracted into diethyl ether $(20 \mathrm{~mL})$. The resulting ethereal solution was washed with a saturated aqueous $\mathrm{NaCl}$ solution $(10 \mathrm{~mL})$ and water $(10 \mathrm{~mL})$, dried over $\mathrm{Na}_{2} \mathrm{SO}_{4}$ and evaporated to dryness. The residue was analysed by ${ }^{1} \mathrm{H}$ NMR.

\section{References}

1. de Mendoza, P.; Echavarren, A. M. Pure Appl. Chem. 2010, 82, 801-820. doi:10.1351/PAC-CON-09-10-06

2. Wang, X.; Zhou, L.; Lu, W. Curr. Org. Chem. 2010, 14, 289-307. doi:10.2174/138527210790231964

3. Kitamura, T. Eur. J. Org. Chem. 2009, 1111-1125. doi:10.1002/ejoc.200801054

4. Vasil'ev, A. V. Russ. J. Org. Chem. 2009, 45, 1-17. doi:10.1134/S1070428009010011

5. Bandini, M.; Emer, E.; Tommasi, S.; Umani-Ronchi, A. Eur. J. Org. Chem. 2006, 3527-3544. doi:10.1002/ejoc.200500995

6. Nevado, C.; Echavarren, A. M. Synthesis 2005, 167-182. doi:10.1055/s-2005-861781

7. Goj, L. A.; Gunnoe, T. B. Curr. Org. Chem. 2005, 9, 671-685. doi:10.2174/1385272053765051

8. Jia, C.; Dongguo, D.; Oyamada, J.; Lu, W.; Kitamura, T.; Fujiwara, Y Science 2000, 287, 1992-1995. doi:10.1126/science.287.5460.1992

9. Jia, C.; Lu, W.; Oyamada, J.; Kitamura, T.; Matsuda, K.; Irie, M.; Fujiwara, Y. J. Am. Chem. Soc. 2000, 122, 7252-7263. doi:10.1021/ja0005845

10. Jia, C.; Kitamura, T.; Fujiwara, Y. Acc. Chem. Res. 2001, 34, 633-639. doi:10.1021/ar000209h

11. Viciu, M. S.; Stevens, E. D.; Petersen, J. L.; Nolan, S. P. Organometallics 2004, 23, 3752-3755. doi:10.1021/om049843f

12. Biffis, A.; Tubaro, C.; Buscemi, G.; Basato, M. Adv. Synth. Catal. 2008, 350, 189-196. doi:10.1002/adsc.200700271

13. Biffis, A.; Gazzola, L.; Gobbo, P.; Buscemi, G.; Tubaro, C.; Basato, M. Eur. J. Org. Chem. 2009, 3189-3198. doi:10.1002/ejoc.200900321

14. Gazzola, L.; Tubaro, C.; Biffis, A.; Basato, M. New J. Chem. 2010, 34, 482-486. doi:10.1039/b9nj00506d

15. Oyamada, J.; Kitamura, T. Chem. Lett. 2005, 34, 1430-1431. doi:10.1246/cl.2005.1430

16. Oyamada, J.; Kitamura, T. Tetrahedron Lett. 2005, 46, 3823-3827. doi:10.1016/j.tetlet.2005.03.179

17. Oyamada, J.; Kitamura, T. Tetrahedron 2006, 62, 6918-6925. doi:10.1016/j.tet.2006.04.080

18. Reetz, M. T.; Sommer, K. Eur. J. Org. Chem. 2003, 3485-3496. doi:10.1002/ejoc.200300260

19. Shi, Z.; He, C. J. Org. Chem. 2004, 69, 3669-3671. doi:10.1021/jo0497353

20. Schipper, D. J.; Hutchinson, M.; Fagnou, K. J. Am. Chem. Soc. 2010, 132, 6910-6911. doi:10.1021/ja103080d

21. Hashimoto, Y.; Hirano, K.; Satoh, T.; Kakiuchi, F.; Miura, M. Org. Lett. 2012, 14, 2058-2061. doi:10.1021/ol300579m And references cited therein

22. Choi, D. S.; Kim, J. H.; Shin, U. S.; Deshmukh, R. R.; Song, C. E. Chem. Commun. 2007, 3482-3484. doi:10.1039/b705719a

23. Yoon, M. Y.; Kim, J. H.; Choi, D. S.; Shin, U. S.; Lee, J. Y.; Song, C. E. Adv. Synth. Catal. 2007, 349, 1725-1737. doi:10.1002/adsc.200700039

24. Li, R.; Wang, S. R.; Lu, W. Org. Lett. 2007, 9, 2219-2222. doi:10.1021/ol070737u

25. Song, C. E.; Jung, D.-u.; Choung, S. Y.; Roh, E. J.; Lee, S.-g. Angew. Chem., Int. Ed. 2004, 43, 6183-6185. doi:10.1002/anie.200460292

26. Tsuchimoto, T.; Maeda, T.; Shirakawa, E.; Kawakami, Y. Chem. Commun. 2000, 1573-1574. doi:10.1039/b003702h

27. Hahsmi, A. S. K.; Rudolph, M. Chem. Soc. Rev. 2012, 41, 2448-2462. doi:10.1039/c1cs15279c 
28. Bandini, M. Chem. Soc. Rev. 2011, 40, 1358-1367. doi:10.1039/c0cs00041h

29. Boorman, T. C.; Larrosa, I. Chem. Soc. Rev. 2011, 40, 1910-1925. doi:10.1039/c0cs00098a

30. Corma, A.; Leyva-Perez, A.; Sabater, M. J. Chem. Rev. 2011, 111, 1657-1712. doi:10.1021/cr100414u

31. Arcadi, A. Chem. Rev. 2008, 108, 3266-3325. doi:10.1021/cr068435d

32. Li, Z.; Brouwer, C.; He, C. Chem. Rev. 2008, 108, 3239-3265. doi:10.1021/cr068434l

33. Skouta, R.; Li, C.-J. Tetrahedron 2008, 64, 4917-4938. doi:10.1016/j.tet.2008.03.083

34. Hashmi, A. S. K. Chem. Rev. 2007, 107, 3180-3211. doi:10.1021/cr000436x

35. Arcadi, A.; Blesi, F.; Cacchi, S.; Fabrizi, G.; Goggiamani, A.; Marinelli, F. Org. Biomol. Chem. 2012, 10, 9700-9708. doi:10.1039/c2ob26763b And references cited therein

36. Vadola, P. A.; Sames, D. J. Org. Chem. 2012, 77, 7804-7814. doi:10.1021/jo3006842

37. Lykakis, I. N.; Efe, C.; Gryparis, G.; Stratakis, M. Eur. J. Org. Chem. 2011, 2334-2338. doi:10.1002/ejoc.201001674

38. Gronnier, C.; Obadachian, Y.; Gagosz, F. Chem. Commun. 2011, 47, 218-220. doi:10.1039/c0cc00033g

39. Jurberg, I. D.; Gagosz, F. J. Organomet. Chem. 2011, 696, 37-41. doi:10.1016/j.jorganchem.2010.06.017

40. Morán-Poladura, P.; Suárez-Pantiga, S.; Piedrafita, M.; Rubio, E.; González, J. M. J. Organomet. Chem. 2011, 696, 12-15. doi:10.1016/j.jorganchem.2010.09.014

41. Menon, R. S.; Findlay, A. D.; Bissember, A. C.; Banwell, M. G. J. Org. Chem. 2009, 74, 8901-8903. doi:10.1021/jo902032p

42. Xiao, F.; Chen, Y.; Liu, Y.; Wang, J. Tetrahedron 2008, 64, 2755-2761. doi:10.1016/j.tet.2008.01.046

43. Curtis, N. R.; Prodger, J. C.; Rassias, G.; Walker, A. J. Tetrahedron Lett. 2008, 49, 6279-6281. doi:10.1016/j.tetlet.2008.08.022

44. Wegner, H. A.; Ahles, S.; Neuburger, M. Chem.-Eur. J. 2008, 14, 11310-11313. doi:10.1002/chem.200801848

45. Gorin, D. J.; Dubè, P.; Toste, F. D. J. Am. Chem. Soc. 2006, 128, 14480-14481. doi:10.1021/ja066694e

46. Nevado, C.; Echavarren, A. M. Chem.-Eur. J. 2006, 11, 3155-3164. doi:10.1002/chem.200401069

47. Hashmi, A. S. K.; Braun, I.; Rudolph, M.; Rominger, F. Organometallics 2012, 31, 644-661. doi:10.1021/om200946m

48. Hashmi, A. S. K.; Yu, Y.; Rominger, F. Organometallics 2012, 31 , 895-904. doi:10.1021/om2008919

49. Hashmi, A. S. K.; Hengst, T.; Lothschütz, C.; Rominger, F. Adv. Synth. Catal. 2010, 352, 1315-1337. doi:10.1002/adsc.201000126

50. Pažicky, M.; Loos, A.; Ferreira, M. J.; Serra, D.; Vinokurov, N.; Rominger, F.; Jäckel, C.; Hashmi, A. S. K.; Limbach, M. Organometallics 2010, 29, 4448-4458. doi:10.1021/om1005484

51. Zeng, X.; Frey, G. D.; Kinjo, R.; Donnadieu, B.; Bertrand, G. J. Am. Chem. Soc. 2009, 131, 8690-8696. doi:10.1021/ja902051m

52. Liu, X.-Y.; Che, C.-M. Angew. Chem., Int. Ed. 2008, 47, 3805-3810. doi:10.1002/anie.200800160

53. Liu, X.-Y.; Ding, P.; Huang, J.-S.; Che, C.-M. Org. Lett. 2007, 9, 2645-2648. doi:10.1021/ol070814l

54. Baron, M.; Tubaro, C.; Basato, M.; Biffis, A.; Natile, M. M.; Graiff, C. Organometallics 2011, 30, 4607-4615. doi:10.1021/om2004145
55. Baron, M.; Tubaro, C.; Basato, M.; Biffis, A.; Graiff, C.; Poater, A.; Cavallo, L.; Armaroli, N.; Accorsi, G. Inorg. Chem. 2012, 51, 1778-1784. doi:10.1021/ic2020786

56. Baron, M.; Tubaro, C.; Basato, M.; Biffis, A.; Graiff, C. J. Organomet. Chem. 2012, 714, 41-46. doi:10.1016/j.jorganchem.2012.02.020

57. de Fremont, P.; Scott, N. M.; Stevens, E. D.; Nolan, S. P. Organometallics 2005, 24, 2411-2418. doi:10.1021/om050111c

58. de Fremont, P.; Singh, R.; Stevens, E. D.; Petersen, J. L.; Nolan, S. P. Organometallics 2007, 26, 1376-1385. doi:10.1021/om060887t

59. Jiang, T.-S.; Tang, R.-Y.; Zhang, X.-G.; Li, X.-H.; Li, J.-H. J. Org. Chem. 2009, 74, 8834-8837. doi:10.1021/jo901963g

60. Jia, C.; Piao, D.; Kitamura, T.; Fujiwara, Y. J. Org. Chem. 2000, 65, 7516-7522. doi:10.1021/jo000861q

61. Marion, N.; Ramón, R. S.; Nolan, S. P. J. Am. Chem. Soc. 2009, 131, 448-449. doi:10.1021/ja809403e

\section{License and Terms}

This is an Open Access article under the terms of the Creative Commons Attribution License

(http://creativecommons.org/licenses/by/2.0), which permits unrestricted use, distribution, and reproduction in any medium, provided the original work is properly cited.

The license is subject to the Beilstein Journal of Organic Chemistry terms and conditions:

(http://www.beilstein-journals.org/bjoc)

The definitive version of this article is the electronic one which can be found at: doi:10.3762/bjoc.9.29 